\title{
Chemical Changes at the Interface Between Low Carbon Steel and an Al-Si Alloy During Solution Heat Treatment
}

\author{
M. Zhe, O. Dezellus, B. Gardiola, M. Braccini, and J.C. Viala
}

(Submitted May 5, 2011; in revised form June 28, 2011)

\begin{abstract}
The aim of this work was to characterize the chemical changes during solid state solution heat treatment of a metallurgically bonded steel/Al-Si interface. For this purpose, low carbon steel plates covered with the A-S7G03 aluminium alloy (7 wt.\% Si, 0.3 wt.\% Mg analogous to A356) were prepared by dip coating, water-quenching to room temperature and reheating in the solid state at 480-560 ${ }^{\circ} \mathrm{C}$ for $3-160 \mathrm{~h}$. Upon reheating at $535{ }^{\circ} \mathrm{C}$, a reaction layer was observed to grow at the interface between steel and the iron-saturated Al-Si alloy. As long as an intimate contact could be maintained, the total thickness, $x$, of the reaction layer increased with time, $t$, according to a nearly parabolic growth law $x^{2}=K \cdot t-b$. At $535{ }^{\circ} \mathrm{C}$, the value of the growth constant was $K=4.045 \times 10^{-14} \mathrm{~m}^{2} \mathrm{~s}^{-1}$. This constant was found to be thermally activated $\left[K=K_{0} \exp (-Q /\right.$ $R T)]$ with $K_{0}=4.37 \times 10^{-4} \mathrm{~m}^{2} \mathrm{~s}^{-1}$ and $Q=153 \mathrm{~kJ} \mathrm{~mol}^{-1}$. The whole chemical interaction process was controlled by solid state volume diffusion and the reaction layer sequence corresponded to a diffusion path in the Al-Fe-Si phase diagram. A striking feature of the reaction process is the unbalanced diffusion of aluminium atoms through the reaction zone which rapidly results in the formation of Kirkendall voids. As these voids coalesce, solid state diffusion becomes more and more difficult and the steel/alloy bond gets weakened. Oxidation appears to be an aggravating factor, where applicable.
\end{abstract}

Keywords aluminium alloys, casting, diffusion paths, interdiffusion, intermetallics, joining, steel

\section{Introduction}

Aluminium-silicon alloy castings are nowadays widely used by the automotive industry in order to meet new antipollution standards by vehicles lightening. However, these alloys have low mechanical performances especially above $100{ }^{\circ} \mathrm{C}$. One of the solutions to improve the performances of aluminium-silicon alloy castings consists in reinforcing them locally with steel or cast iron inserts. Such locally reinforced castings are, for example, produced for use in automotive vehicles as engine cylinder blocks,${ }^{[1]}$ crankcases or pistons. ${ }^{[2,3]}$ When these parts are made by conventional die casting or injection moulding techniques, inserts are simply embedded in the light alloy after complete solidification. The fretting stress field thus created may be sufficient for certain applications. ${ }^{[4]}$ However, for a perfect tightness and an optimum load transfer with good thermal and electrical conductivities, a sound metallurgical bond of the same type as that which can be found in assemblies produced by laser or arc welding ${ }^{[5]}$ has to be formed at the insert/alloy interface. This is achieved by using specific

M. Zhe, O. Dezellus, B. Gardiola, and J.C. Viala, Université Claude Bernard Lyon 1, LMI, UMR CNRS $\mathrm{N}^{\circ} 5615,43 \mathrm{Bd}$ du 11 novembre 1918, 69622 Villeurbanne Cedex, France; M. Braccini, Grenoble Université, SIMAP, UMR CNRS № 5266, BP 7538422 St. Martin d'Hères Cedex, France. Contact e-mail: olivier.dezellus@univ-lyon1.fr. insert moulding techniques such as ultrasonic vibration assisted casting, ${ }^{[6]}$ expendable pattern casting ${ }^{[7]}$ or the "Alfin" process ${ }^{[8]}$ still employed today to bond nickel austenitic cast iron ring carriers to pistons.

A first difficulty that arises when the last-mentioned technique is used is the growth by chemical reaction of brittle intermetallic compounds at the insert/alloy interface. This chemical reactivity of ferrous substrates with aluminium-silicon alloys in the liquid state has already been the subject of a lot of investigations. ${ }^{[4,7-19]}$ By carefully controlling the casting procedure and the cooling rate, growth of these compounds between an iron base insert and Al-Si alloys can be limited such that the total thickness of the reaction zone does not exceed a few micrometers. Under these conditions, a mechanically strong and tough bond can be established at the insert/alloy interface. ${ }^{[20-22]}$

When aluminium-silicon alloys such as $\mathrm{AlSi} 5 \mathrm{Cu} 3 \mathrm{Mg}$ (A-S5U3G) or AlSi7Mg0.3 (A-S7G03) are used to produce moulded parts by conventional casting, a thermal treatment designated as T6 is generally applied, consisting of the following steps: isothermal holding at $520-540{ }^{\circ} \mathrm{C}$ (793$813 \mathrm{~K}$ ) for $20-10 \mathrm{~h}$, quenching in cold water and finally ageing for $5-10 \mathrm{~h}$ at $170-180{ }^{\circ} \mathrm{C}(443-453 \mathrm{~K})$. This treatment, which combines solution heat treatment with spheroidization of silicon second phase and age hardening, has the beneficial effects of increasing both the ultimate tensile strength (by about $50 \%$ ) and the $0.2 \%$ proof stress (by a factor of 2) ${ }^{[23,24]}$ It should therefore be very interesting to apply the T6 heat treatment to bimetallic castings produced by insertion moulding.

This however poses the question of further changes by chemical reaction of the interface transition zone when reheated at $520-540{ }^{\circ} \mathrm{C}(793-813 \mathrm{~K})$, changes which may 


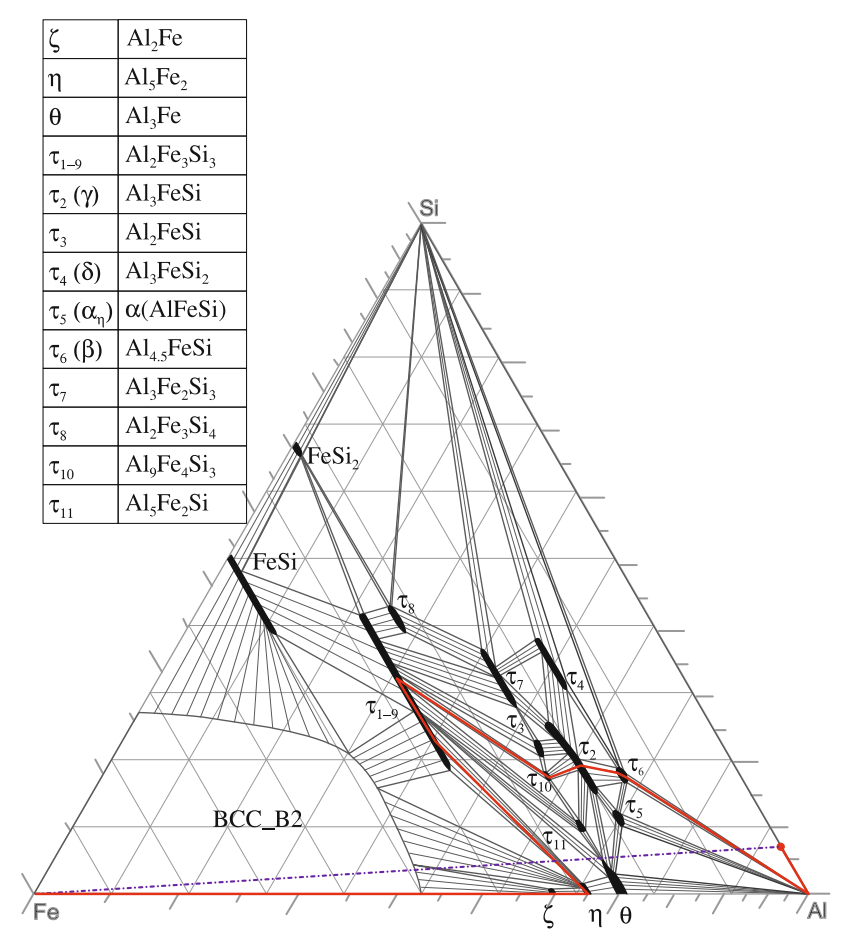

Fig. 1 Experimental Al-Fe-Si isothermal section at $555^{\circ} \mathrm{C}$ $(828 \mathrm{~K})$ and below, after Ref $25-29$. Grid in atomic fraction, axes in wt.\%. The continuous bold line going from A-S7 to Fe represents the stationary diffusion path, details of which will be given in section 3.2.4

affect the mechanical behaviour of the insert/alloy joint. Since data concerning $\mathrm{Fe} / \mathrm{Al}-\mathrm{Si}$ chemical interaction in the solid state are very scarce, an experimental study has been undertaken to investigate this issue. The present paper more especially deals with the solid state chemical reactions likely to develop during solution treatment at the interface between low carbon steel and the A-S7G03 aluminium foundry alloy. For this purpose, heat treatments were first carried out on steel plates covered with a thin Al-Si alloy layer by dip-coating. To simulate more accurately an insertion moulded part, AS7G03 conical cylinders with a steel plate inserted in them were also prepared and heat-treated. The results will be discussed in terms of solid-state reaction-diffusion in the AlFe-Si ternary system. For the sake of clarity, a section of the Al-Fe-Si ternary phase diagram featuring all the binary and ternary compounds stable at $555^{\circ} \mathrm{C}(828 \mathrm{~K})$ and below is presented in Fig. 1. Based on literature data ${ }^{[25-27]}$ and experimental results, ${ }^{[28,29]}$ the compound compositions and phase equilibria reported in this section were also used for the latest updates and assessments of the Al-Fe-Si system. ${ }^{[30-33]}$

\section{Experimental Section}

\subsection{Starting Materials}

The aluminium base casting alloy used in the present study contained $\sim 7$ wt. $\%$ of silicon and $\sim 0.3$ wt. $\%$ of $\mathrm{Mg}$
Table 1 Chemical composition (in wt.\%) of the A-S7G03 alloy as reported in the supplier specification sheet under the commercial designation Calypso 67R

\begin{tabular}{ll}
\hline Element & Content, wt.\% \\
\hline $\mathrm{Si}$ & $6.7-7.3$ \\
$\mathrm{Mg}$ & $0.3-0.4$ \\
$\mathrm{Sb}$ & $0.12-0.16$ \\
$\mathrm{Fe}$ & 0.14 \\
$\mathrm{Ti}$ & $0.1-0.15$ \\
$\mathrm{Cu}$ & 0.02 \\
$\mathrm{Mn}$ & 0.04 \\
$\mathrm{Ni}$ & 0.02 \\
$\mathrm{Zn}$ & 0.04 \\
$\mathrm{Al}$ & Balance
\end{tabular}

Table 2 Chemical composition (in wt.\%) of the hot-dipped galvanized XES low carbon steel sheets: (a) supplier specifications, (b) redetermination by SCA CNRS (F 69360 Solaize)

\begin{tabular}{llr}
\hline & \multicolumn{2}{c}{ Content, wt.\% } \\
\cline { 2 - 3 } Element & (a) & (b) \\
\hline $\mathrm{C}$ & 0.002 & 0.03 \\
$\mathrm{Mn}$ & 0.105 & 0.2 \\
$\mathrm{P}$ & 0.009 & \\
$\mathrm{~S}$ & 0.006 & 0.017 \\
$\mathrm{Si}$ & 0.006 & \\
$\mathrm{Al}$ & 0.034 & 2.72 \\
$\mathrm{Ti}$ & 0.068 & 96.46 \\
$\mathrm{Zn}$ & $2.8(2 \times 10 \mu \mathrm{m}$ of pure $\mathrm{Zn})$ & \\
$\mathrm{Fe}$ & Balance & \\
\hline
\end{tabular}

with $\mathrm{Sb}$ as refining agent: its precise composition is given in Table 1. In the following, this alloy of the 4000 series analogous to A356 will be designated as A-S7G03.

Hot-dip galvanized sheets of low carbon steel were also used. With a mean thickness of $0.77 \mathrm{~mm}$ (including a $10 \mu \mathrm{m}$ zinc coating on each side), these steel sheets had the composition reported in Table 2. For most experiments, they were cut by spark machining into small plates $0.77 \mathrm{~mm} \times 10 \mathrm{~mm} \times 60 \mathrm{~mm}$. In the following, these plates will be designated as XES. Because of the high solubility of $\mathrm{Zn}$ in $\mathrm{Al}$, the thin $\mathrm{Zn}$ layer present on XES steel is dissolved during the aluminizing step in the A-S7G melt and next, after solidification, in the $\alpha$-Al solid solution. As a consequence, $\mathrm{Zn}$ does not segregate during the whole process and therefore it is not detected neither in the interfacial reaction layer nor in the solidified A-S7G alloy.

\subsection{Sample Preparation and Heat Treatment}

To coat XES steel plates with a thin A-S7G03 alloy layer, the plates were vertically immersed in $100 \mathrm{~g}$ of liquid alloy held at a temperature of $680 \pm 3{ }^{\circ} \mathrm{C}(953 \mathrm{~K})$. Melting was 
achieved by direct radio-frequency (RF) coupling of the alloy contained in a conical alumina crucible $(20-40 \mathrm{~mm}$ in diameter). The temperature was controlled with a $K$ thermocouple probe (from the Chauvin-Arnoux company) plunging into the melt. Dissolution of the $10 \mu \mathrm{m}$ thick zinc coating in the liquid bath upon immersion greatly facilitated good wetting of steel by the alloy, as already reported. ${ }^{[7]}$ For even better results, each face of the plate was also mechanically scraped during the time the melt was held at $680{ }^{\circ} \mathrm{C}(953 \mathrm{~K})$. After $40 \mathrm{~s}$ at that temperature, each plate was very rapidly pulled out of the melt and water-quenched (cooling rate of the order of $500 \mathrm{~K} \mathrm{~s}^{-1}$ ).

A-S7G03 blocks with an XES plate inserted in them were also prepared. In this case, the same procedure as before was used but after $40 \mathrm{~s}$ immersion at $680{ }^{\circ} \mathrm{C}(953 \mathrm{~K})$, the RF power was turned off to allow the melt with the steel plate immersed in it to cool in the crucible. Complete solidification of the melt took about $120 \mathrm{~s}$ (average cooling rate of $1 \mathrm{~K} \mathrm{~s}^{-1}$ ). After cooling to room temperature, the conical alloy block with the steel plate inserted in it was cut perpendicular to its axis into several $5 \mathrm{~mm}$ thick slices.

The thin aluminized plates or the thick slices were then solution heat-treated in ambient air to simulate conditions commonly used in foundries. Most of the samples were heattreated at $535 \pm 3{ }^{\circ} \mathrm{C}(808 \mathrm{~K})$ for durations varying from 3 to $160 \mathrm{~h}$. In order to avoid excessive damage to the reaction zones grown during solution treatment, the samples were not water-quenched at the end of the solution treatment but aircooled down to room temperature. Some additional heattreatments were also performed to investigate the effects of varying the temperature and changing the silicon content.

\subsection{Sample Characterization}

For both types of sample, cross-sections perpendicular to the insert/alloy interface were diamond sawn and diamond polished to a finish better than $1 \mu \mathrm{m}$ for systematic examination by optical microscopy (OM) and scanning electron microscopy (SEM). The as-prepared sections were also characterized by electron probe microanalysis (EPMA) using a CAMECA CAMEBAX apparatus operated under $10 \mathrm{kV}$ with a beam current of $11 \mathrm{nA}$. The counting rates measured for the $\mathrm{K} \alpha$ radiation of $\mathrm{Al}, \mathrm{Si}$ and $\mathrm{Fe}$ by energy dispersive spectrometry in each point were referred to pure standards of the elements and corrected for atomic number, absorption and fluorescence. Several concentration profiles for $\mathrm{Al}, \mathrm{Fe}$ and $\mathrm{Si}$ at the crossing of the reaction zones were established point by point with a lateral resolution of $\pm 0.7 \mu \mathrm{m}$. The crystal nature of the phases present in the reaction zones was characterized by $\mathrm{x}$-ray diffraction (XRD, $\mathrm{K} \alpha \mathrm{Cu}$ radiation) using an X'Pert Pro MPD diffractometer equipped with a back monochromator and an X'Celerator detector (Panalytical). To this end, some aluminized and heat-treated plates were subjected to a chemical etching at room temperature in an alkaline aqueous solution $(\mathrm{NaOH}$ $1 \mathrm{M})$ so that all the Al-Si alloy coating was eliminated, revealing the external part of the reaction zone. Thin reaction zones (less than $10 \mu \mathrm{m}$ ) were directly characterized whereas for thicker ones, several XRD spectra were recorded after layer-by-layer mechanical abrasion parallel to the steel substrate surface.

\section{Results and Discussion}

\subsection{Constitution of the Steel/Alloy Transition Zones Before Heat Treatment}

3.1.1 XES Plates Aluminized by Dip-Coating. When observed by OM through a transverse section, the XES steel plates simply dip-coated at $680{ }^{\circ} \mathrm{C}(953 \mathrm{~K})$ in the A-S7G03
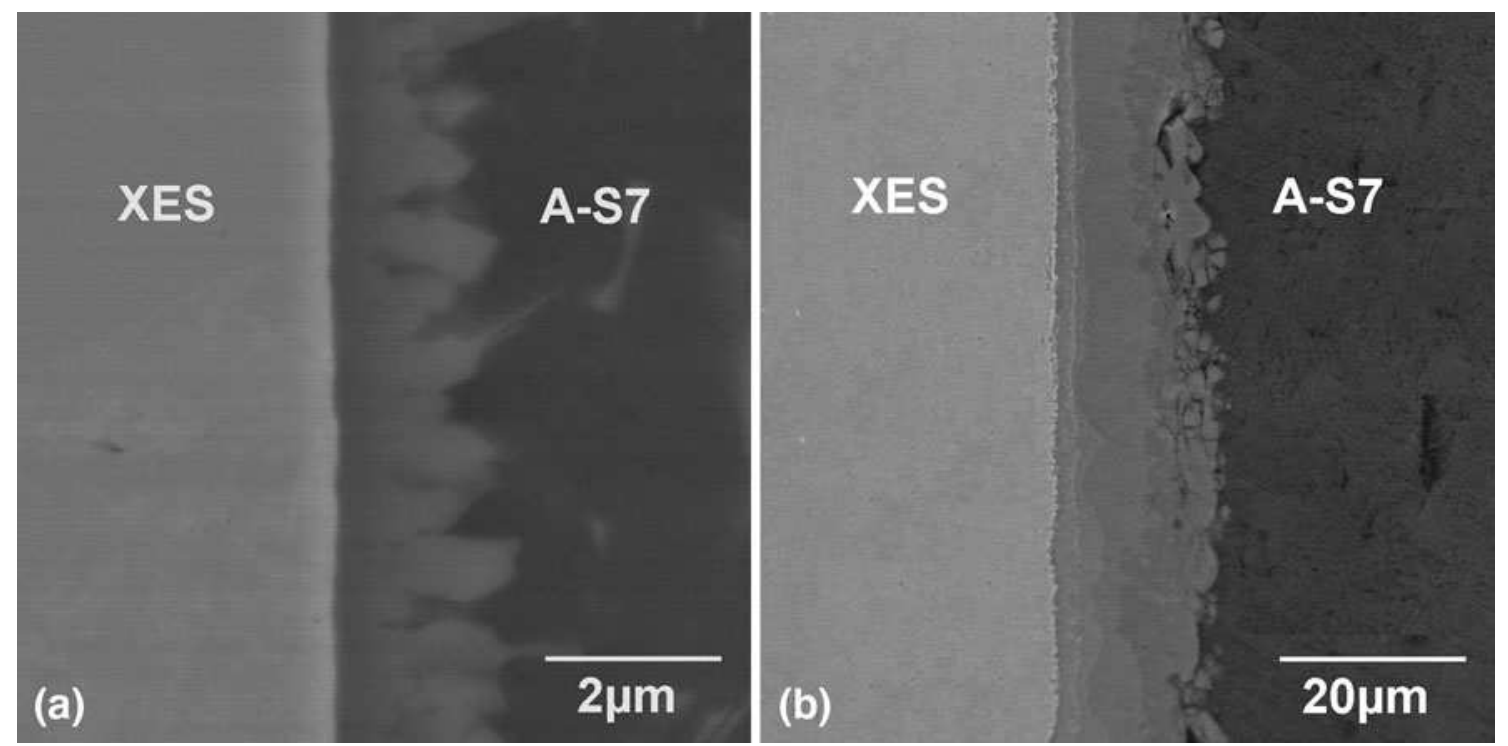

Fig. 2 The XES/A-S7G03 interface transition zone morphology, as revealed by SEM: (a) in XES plates simply aluminized by dip-coating; (b) in moulded blocks with a XES insert 
alloy and water-quenched were covered with a continuous and strongly adherent A-S7G03 alloy film with a very finegrained microstructure. The thickness of this film generally varied from 50 to $150 \mu \mathrm{m}$ but could occasionally attain $400 \mu \mathrm{m}$ in some places. A metallurgical bond was established at the XES/A-S7G03 interface in the form of a continuous reaction layer with a thickness not exceeding $2 \mu \mathrm{m}$ (Fig. 2a). EPMA and XRD showed that this layer mainly consisted of the $\tau_{5}$ ternary compound with hexagonal symmetry ( $a=1.2404 \mathrm{~nm} ; c=2.6234 \mathrm{~nm})$, also designated as $\alpha$-AlFeSi or $\mathrm{Al}_{7.4} \mathrm{Fe}_{2} \mathrm{Si}$. According to the latest assessments of the Al-Fe-Si phase diagram, ${ }^{[31,32]}$ the ternary compound $\tau_{5}$ is in equilibrium with an Al-Si liquid phase containing from 6 to $11 \mathrm{wt} \% \mathrm{Si}$ at $680{ }^{\circ} \mathrm{C}(953 \mathrm{~K})$. It is thus logical to find this compound as the major reaction product at the surface of steel plates dip-coated at that temperature in an aluminium alloy containing 7 wt.\% Si.

3.1.2 Moulded XES/A-S7G03 Blocks. For as cast XES/ A-S7G03 blocks, the steel insert was also metallurgically bonded to the light alloy but the latter had a coarse-grained microstructure and the intermediate layer formed by chemical reaction at the interface was much thicker: $14-17 \mu \mathrm{m}$ instead of 1-2 $\mu \mathrm{m}$ (see Fig. 2b). The only difference between the two kinds of sample was in the cooling rate which was very fast for dip-coated specimens $\left(\sim 500 \mathrm{~K} \mathrm{~s}^{-1}\right)$ and much slower for blocks $\left(\sim 1 \mathrm{~K} \mathrm{~s}^{-1}\right)$. The thick interface transition zone present in the blocks was then formed upon slow cooling. According to XRD, SEM and EDS results, it consisted of three sub-layers: a thin inner layer of $\eta \mathrm{Al}_{5} \mathrm{Fe}_{2}$ in contact with steel, $\mathrm{a} \sim 6 \mu \mathrm{m}$ thick intermediate layer of $\tau_{5}$ $\left(\mathrm{Al}_{7.4} \mathrm{Fe}_{2} \mathrm{Si}\right)$ and $\mathrm{a} \sim 6 \mu \mathrm{m}$ thick outer layer of $\tau_{6}\left(\mathrm{Al}_{4.5} \mathrm{FeSi}\right)$ in contact with the alloy. These observations are in good agreement with previous results obtained under similar conditions. ${ }^{[21]}$ Referring to experimental data ${ }^{[13,34]}$ and to thermodynamic evaluations, ${ }^{[27,31,32]}$ it can be specified that the two outer layers of $\tau_{5}$ and $\tau_{6}$ were successively formed by crystallization from the Al-Si liquid alloy saturated in iron whereas $\eta \mathrm{Al}_{5} \mathrm{Fe}_{2}$ began to grow by solid state diffusion.

\subsection{The Reaction Zone in Aluminized Steel Plates After Heat Treatment}

3.2.3 Constitution of the Reaction Zones Grown at $535{ }^{\circ} \mathbf{C}$. The effect of the solution heat treatment was first investigated on XES plates aluminized by dip-coating in the A-S7G03 alloy. When these plates were reheated at $535{ }^{\circ} \mathrm{C}$ $(808 \mathrm{~K})$ for increasing periods of time, a multi phase reaction zone was observed to grow at the steel/alloy interface.

For short duration heat treatments, $3 \mathrm{~h}$ or less, this reaction zone mainly consisted of two different sub-layers as shown in Fig. 3: a thick medium grey inner layer at the steel side and a thin and bright outer layer with crystal outgrowths at the alloy side. The inner layer exhibited a complex microstructure with second-phase precipitates whereas the outer layer had a single-phase appearance. Typical concentration profiles established by EPMA for Al, $\mathrm{Fe}$ and $\mathrm{Si}$ at the crossing of the XES/A-S7G03 interface after $3 \mathrm{~h}$ of isothermal holding at $535^{\circ} \mathrm{C}(808 \mathrm{~K})$ are reported in Fig. 4. It can be seen that at the both ends of the reaction zone (from 2 to $8 \mu \mathrm{m}$ and from 15 to $17 \mu \mathrm{m}$ in Fig. 4, respectively), the contents of the three elements remain nearly constant. These contents are characteristic for the pure ternary compound $\tau_{6}$ in the outer part in contact with the A-S7G03 alloy and for the binary compound $\eta \mathrm{Al}_{5} \mathrm{Fe}_{2}$ in the inner part in contact with steel. Identification of these two compounds was confirmed by the observation of their characteristic x-ray diffraction lines after alkaline etching and mechanical abrasion. The 1.5 at.\% Si found in $\eta \mathrm{Al}_{5} \mathrm{Fe}_{2}$ by EPMA can be explained, in part, by the replacement of some aluminium atoms by silicon atoms. The remainder of this 1.5 at.\% $\mathrm{Si}$ is contained in the small dark grey inclusions distributed throughout the phase.

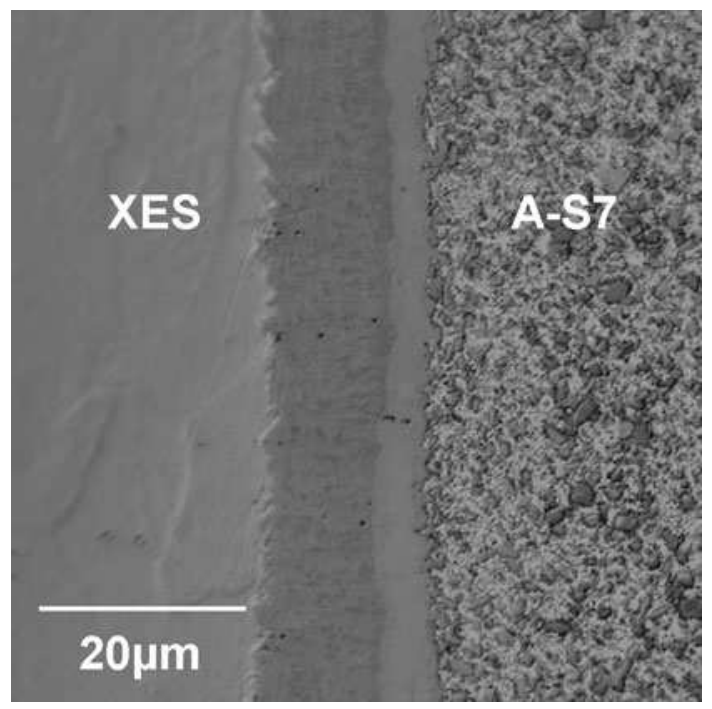

Fig. 3 Optical micrograph of the XES/A-S7G03 reaction zone after $3 \mathrm{~h}$ of isothermal holding at $535{ }^{\circ} \mathrm{C}(808 \mathrm{~K})$

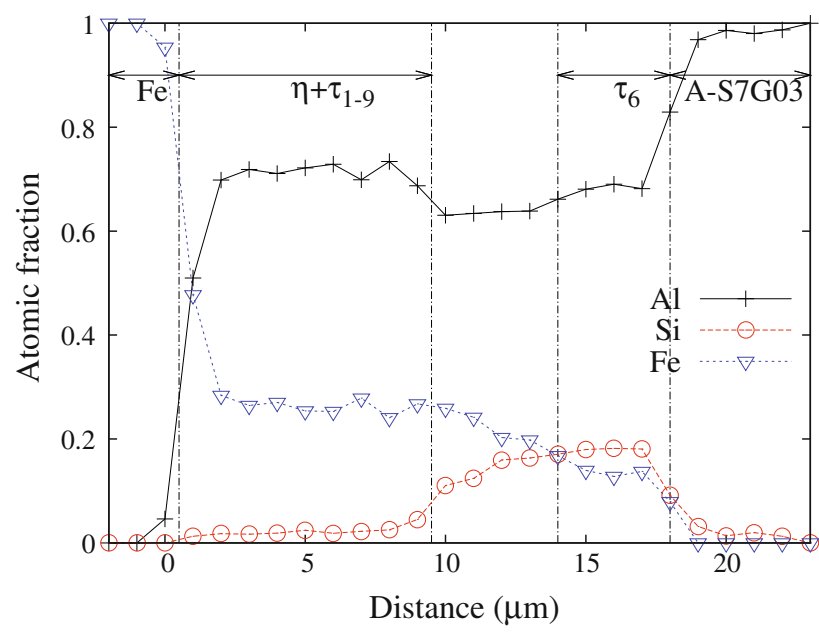

Fig. 4 EPMA concentration profiles for $\mathrm{Al}, \mathrm{Fe}$ and $\mathrm{Si}$ at the crossing of the XES/A-S7G03 reaction zone shown in Fig. 3, i.e. after $3 \mathrm{~h}$ isothermal holding at $535^{\circ} \mathrm{C}(808 \mathrm{~K})$ 
Indeed these inclusions, that are always present in $\eta \mathrm{Al}_{5} \mathrm{Fe}_{2}$ layers grown from Al-Si alloys, ${ }^{[13]}$ consist of a silicon-rich phase, namely the triclinic $\tau_{1-9}$ ternary compound with approximate chemical formula $\mathrm{Al}_{2} \mathrm{Fe}_{3} \mathrm{Si}_{3}$. Between the two sub-layers of $\eta \mathrm{Al}_{5} \mathrm{Fe}_{2}+\tau_{1-9}$ and $\tau_{6}$, lies a transition zone in which the Si content regularly increases while the $\mathrm{Al}$ and $\mathrm{Fe}$ contents decrease (from 9 to $14 \mu \mathrm{m}$ in Fig. 4). Such a change over a distance larger than $1.4 \mu \mathrm{m}$, the lateral resolution of EPMA, is characteristic for the crossing of a multiphase transition zone but at this stage, further phase identification was difficult. Special attention was paid to the compound $\tau_{5}$ since it was the major constituent of the $1-2 \mu \mathrm{m}$ thick reaction layer initially present before heat treatment. Therefore, this compound was searched for but neither EPMA nor DRX provided any indication of its persistence in the reaction zone after $3 \mathrm{~h}$ growing at $535{ }^{\circ} \mathrm{C}$ (808 K).

For medium duration heat treatments $(10<t<20 \mathrm{~h})$, interface reaction zones thicker than previously were obtained. As shown in Fig. 5 and 6, the bright single-phase $\tau_{6}$ sub-layer was still present at the outer part in contact with the aluminium alloy. The inner $\eta+\tau_{1-9}$ sub-layer with its typical serrated morphology was also present at the steel side. Moreover, a third dark-grey sub-layer became clearly visible between the $\eta+\tau_{1-9}$ and $\tau_{6}$ sub-layers (Fig. 5). In fact, this third sub-layer grown between 3 and $15 \mathrm{~h}$ of isothermal holding corresponded to an enlarged multiphase transition zone having the same nature as that already revealed by EPMA in Fig. 4. The thickness of this transition zone approaching $10 \mu \mathrm{m}$ after $20 \mathrm{~h}$ of isothermal holding, attempts were made to characterize its constituent phases. After chemical etching of the Al-Si alloy and mechanical abrasion over increasing depths, XRD clearly confirmed the presence of $\tau_{6}$ and $\eta$ at the outer and inner sides of this transition zone, respectively. In the transition zone itself,

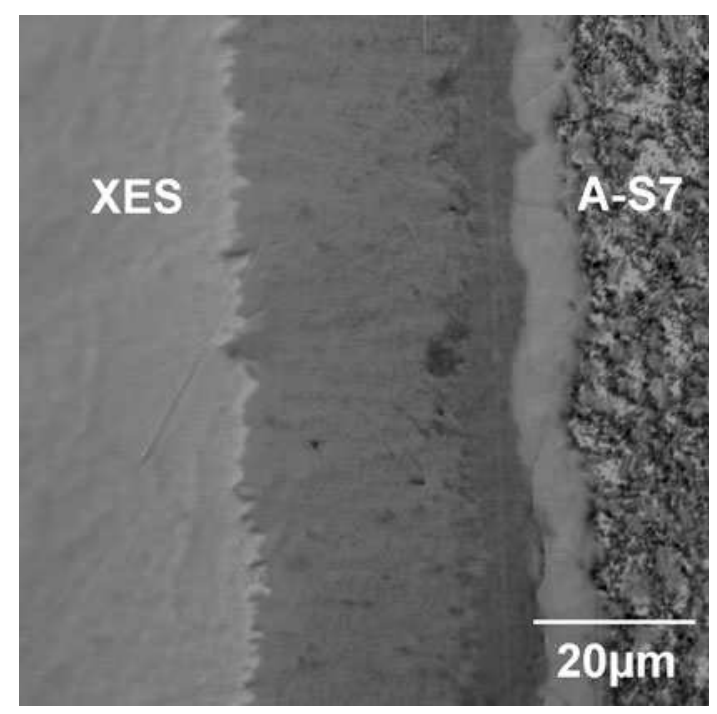

Fig. 5 The XES/A-S7G03 transition zone after $15 \mathrm{~h}$ of isothermal holding at $535{ }^{\circ} \mathrm{C}(808 \mathrm{~K})$. Note the increase in thickness and the appearance of a third sub-layer by comparison with Fig. 3 two ternary compounds could be unambiguously characterized by XRD: $\tau_{1-9}$ which gave weak but numerous and characteristic diffraction lines and $\tau_{10} \mathrm{Al}_{9} \mathrm{Fe}_{4} \mathrm{Si}_{3}$ for which many strong diffraction lines fitted very well with the angular positions and intensities reported by Krendelsberger et al. ${ }^{[29]}$ (hexagonal symmetry with $a=1.5518 \mathrm{~nm}$ and $c=0.7297 \mathrm{~nm}$ ).

For long heat treatment times at $535^{\circ} \mathrm{C}(808 \mathrm{~K})$, $t>40 \mathrm{~h}$, not three but four distinct sub-layers were identified in the interface reaction zone that continued to grow between the low carbon steel plate and the A-S7G03 alloy film surrounding it, as shown in Fig. 7. It can be seen from the EPMA results reported in Fig. 8 that the $\mathrm{Al}, \mathrm{Fe}$ and

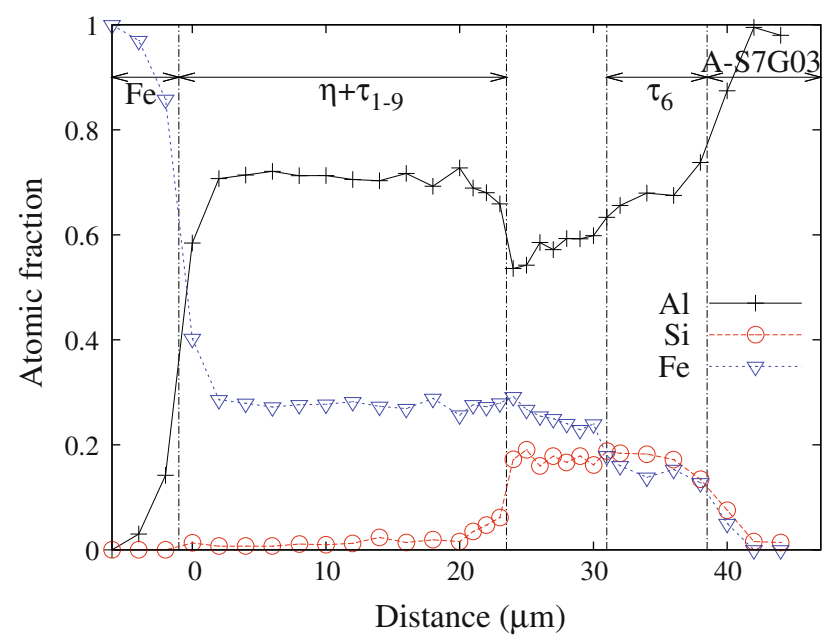

Fig. $6 \mathrm{Al}, \mathrm{Fe}$ and $\mathrm{Si}$ concentration profiles across the XES/A$\mathrm{S} 7 \mathrm{G} 03$ reaction zone shown in Fig. 5 , i.e. after $15 \mathrm{~h}$ of isothermal holding at $535^{\circ} \mathrm{C}(808 \mathrm{~K})$

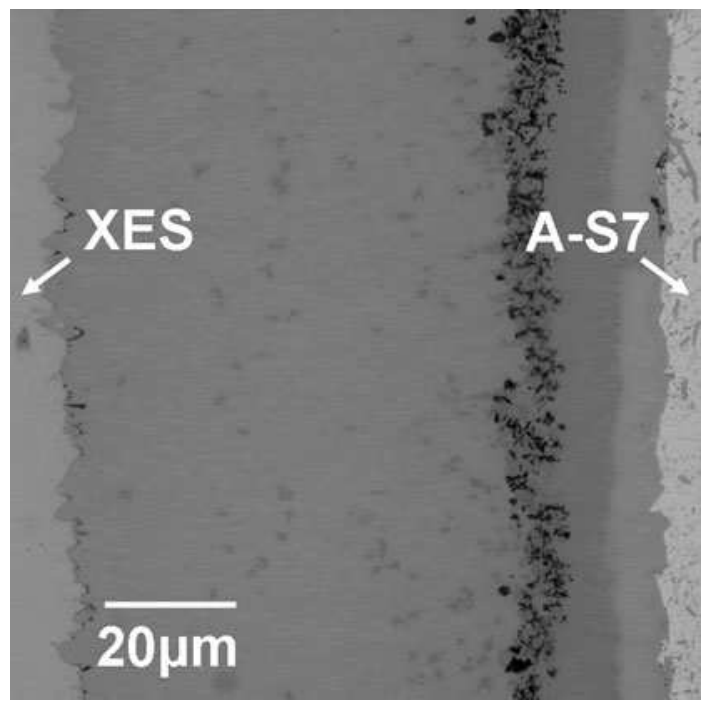

Fig. 7 The XES/A-S7G03 reaction zone after $72 \mathrm{~h}$ of isothermal holding at $535{ }^{\circ} \mathrm{C}(808 \mathrm{~K})$. Four different sub-layers are clearly distinguishable on the XES substrate. Black points in the second sub-layer are pores 
Si contents tended to remain constant in each of the four sub-layers. This means that the layers tended to become homogeneous or single-phase, except for the first thick inner sub-layer which invariably consisted of the $\eta \mathrm{Al}_{5} \mathrm{Fe}_{2}$ phase with dark-grey inclusions of the compound $\tau_{1-9}$ dispersed in it $(d \approx 1 \mu \mathrm{m}$, Fig. 7). Although present throughout the whole $\eta \mathrm{Al}_{5} \mathrm{Fe}_{2}$ sub-layer, the dark-grey $\tau_{1-9}$ inclusions were also observed to gather together at its outer part where they formed a second and new sub-layer with a silicon content of 25-27 at.\% (Fig. 7). The third sub-layer was previously a multi-phase transition zone in which the $\mathrm{Al}, \mathrm{Fe}$ and $\mathrm{Si}$ contents varied continuously. This third sub-layer has now acquired a constant composition over a depth of nearly $10 \mu \mathrm{m}$. More precisely, its average composition which is $\mathrm{Al}: \mathrm{Fe}: \mathrm{Si}=56: 25: 19$ in at.\% matches that of the ternary compound $\tau_{10} \quad \mathrm{Al}_{9} \mathrm{Fe}_{4} \mathrm{Si}_{3}$ already identified by XRD after $20 \mathrm{~h}$ of isothermal holding. Finally, the outer sub-layer in contact with the aluminium alloy film has the same composition as previously, namely $\mathrm{Al}: \mathrm{Fe}: \mathrm{Si}=66: 16: 18$ in at. $\%$, which is the composition of the ternary compound $\tau_{6}$. It is worth noting that between $\tau_{10}$ and $\tau_{6}$, three points in the profile between 91.5 and $92 \mu \mathrm{m}$ match the composition of $\tau_{2}(\mathrm{Al}: \mathrm{Fe}: \mathrm{Si}=62: 18: 20$ in at.\%). The same observation was made in other places. Although not readily characterized by $\mathrm{XRD}$, according to the isothermal section at $555^{\circ} \mathrm{C}$ (see Fig. 1), the presence of the compound $\tau_{2}$ between $\tau_{10}$ and $\tau_{6}$ is very likely.

It should be noted that for all diffusion couples prepared, a single-phase transition zone depleted in silicon was observed in the Al-Si alloy adjoining the reaction zone. The thickness of this zone free of silicon crystals, which will be designated as $\mathrm{Al}$, remained however limited: it did not exceed $15 \mu \mathrm{m}$ after $72 \mathrm{~h}$ of isothermal holding (Fig. 8). As for the A-S7G03 alloy located farther away, it always contained in addition to silicon crystals small platelets with a bright contrast in SEM which analysed for $\tau_{6}$ by EPMA. The fact that these $\tau_{6}$ platelets were present in all samples studied clearly indicates that in the solid state, the A-S7G03

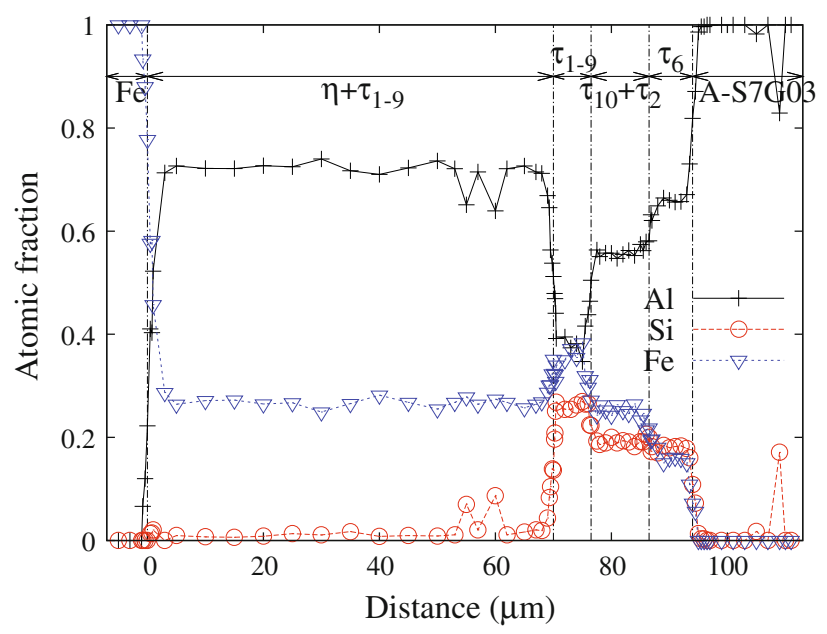

Fig. $8 \mathrm{Al}, \mathrm{Fe}$ and $\mathrm{Si}$ concentration profiles across the XES/AS7G03 reaction zone shown in Fig. 7, i.e. after $72 \mathrm{~h}$ of isothermal holding at $535^{\circ} \mathrm{C}(808 \mathrm{~K})$ alloy became saturated in iron even for the shortest heattreatment durations.

Another point which is worthy of note is that when the heat treatment duration increased, reaction zones representative of the chemical interaction process under study were more and more difficult to observe for two main reasons: first, observations after long-term treatment were limited to places where the thickness of the alloy film was sufficient to properly feed aluminium and silicon to the growing reaction layer, namely more than $100 \mu \mathrm{m}$ for a reaction zone with a total thickness of $50 \mu \mathrm{m}$; secondly, more and more holes appeared at the interface between the aluminium alloy and the $\tau_{6}$ outer layer and the quality of the contact between the constituents was degraded.

3.2.4 Variation in Layer Thickness with Reaction Time. Figure 9 summarizes the average thicknesses measured for the different reaction sub-layers in XES/A-S7G03

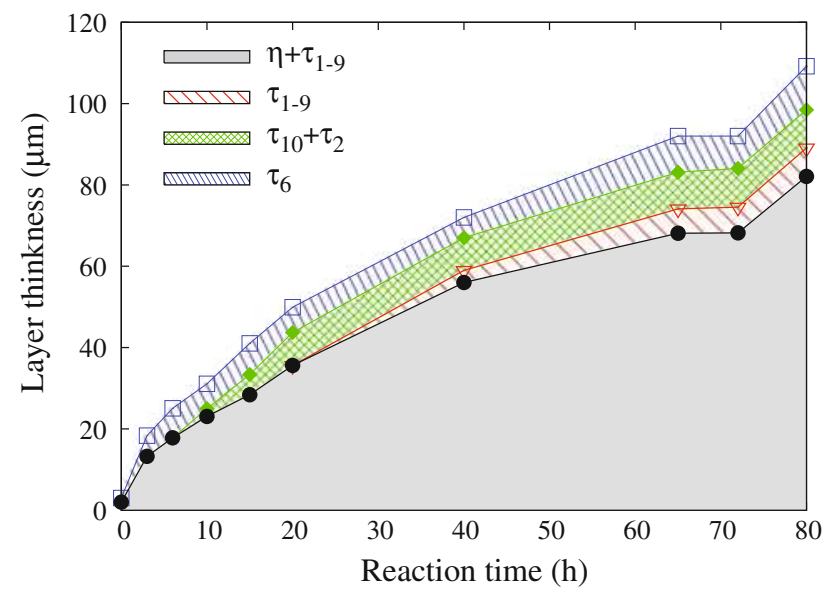

Fig. 9 Variation with reaction time of the thickness of the whole reaction zone and of its constituent sub-layers $\eta+\tau_{1-9}$, $\tau_{1}, \tau_{10}+\tau_{2}$ and $\tau_{6}$ in aluminized XES steel plates heat-treated at $535{ }^{\circ} \mathrm{C}(808 \mathrm{~K})$ for different times

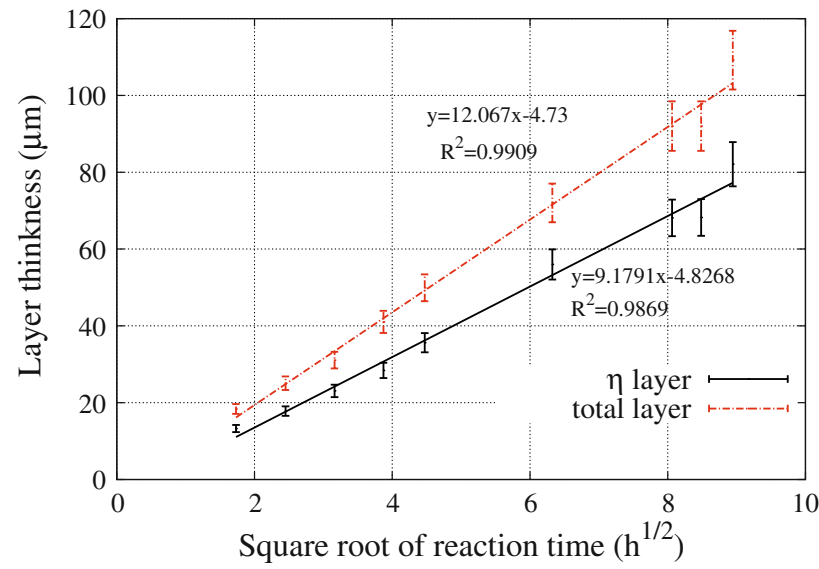

Fig. 10 Nearly parabolic growth of the whole reaction layer and of the $\eta+\tau_{1-9}$ sub-layer for aluminized XES steel plates heat-treated at $535^{\circ} \mathrm{C}(808 \mathrm{~K})$ for increasing times 
samples heat-treated at $535^{\circ} \mathrm{C}(808 \mathrm{~K})$ for increasing durations. For sake of clarity, errors bars are not shown in this figure. The general trend for each sub-layer as well as for the whole reaction layer is a decrease in the growth rate, $d x / d t$, as the thickness, $x$, increases, suggesting a parabolic growth law. The total thickness of the reaction layer and that of the $\eta+\tau_{1-9}$ sub-layer were then replotted, with their error bars, as a function of the square root of the reaction time, $t$, in Fig. 10. Note that an increase in the holding time is associated with an increase in the dispersion of thickness measurements along the interface. This is due to the local rupture of the diffusion path either by formation of Kirkendall voids (see section 3.2.4) or by internal oxidation following oxygen penetration. This explains why in Fig. 10 the error bars beyond $60 \mathrm{~h}$ are the widest. Within the error bar on the experimental measurements, a linear dependence is obvious for both series represented in Fig. 10. In particular, the experimental points representing the thickness of the whole reaction layer are well fitted by the following parabolic growth law:

$x^{2}=K \cdot t-b$

With $x$ and $t$ expressed in meters and seconds, respectively, the value of the rate constant, $K$, is $K=4.045 \times$ $10^{-14} \mathrm{~m}^{2} \mathrm{~s}^{-1}$. An analogous parabolic equation is valid for the $\eta+\tau_{1-9}$ sub-layer with $K=2.34 \times 10^{-14} \mathrm{~m}^{2} \mathrm{~s}^{-1}$. It was noted that $\tau_{5}$, the major reaction product in the simply aluminized samples, is rapidly converted during solid state solution treatment into other compounds. Such a conversion should, however, need a certain time and this may justify why the parabolic growth of the reaction layer is a little delayed. Other examples of delayed parabolic growth are given in Ref 35.

3.2.5 Effect of Temperature. Additional experiments were carried out by heat-treating XES/A-S7G03 samples at different temperatures ranging from 470 to $555{ }^{\circ} \mathrm{C}$ (743$828 \mathrm{~K}$ ). Only the thickness of the reaction zone was observed to increase with the treatment temperature; neither the morphology in two, three or four sub-layers nor the composition of the sub-layers was notably affected. The values of the parabolic growth constant, $K$, determined at each temperature for the total reaction layer were plotted in Arrhenius coordinates in Fig. 11. Within the error bar on each determination, the temperature dependence of the growth constant, $K$ in $\mathrm{m}^{2} \mathrm{~s}^{-1}$, can be expressed by the equation:

$K=K_{0} \exp (-Q / R T)$

where $R$ is the gas constant $\left(R=8.314 \mathrm{~J} \mathrm{~K}^{-1} \mathrm{~mol}^{-1}\right), Q$ the activation energy in $\mathrm{J} \mathrm{mol}^{-1}$ and $T$ the temperature in Kelvin. After conversion, the least squares method yields $K_{0}=4.37 \times 10^{-4} \mathrm{~m}^{2} \mathrm{~s}^{-1}$ and $Q=153 \mathrm{~kJ} \mathrm{~mol}^{-1}$. These values correspond to the solid straight line drawn in Fig. 11. Of course, Eq 2 is also applicable to the $\eta+\tau_{1-9}$ inner sub-layer: $Q$ keeps the same value whereas $K_{0}$ is slightly smaller $\left(2.46 \times 10^{-4} \mathrm{~m}^{2} \mathrm{~s}^{-1}\right)$.

For pure iron immersed in a bath of molten aluminium saturated in iron, parabolic growth proceeds with an activation energy $Q$ in the range $90-120 \mathrm{~kJ} \mathrm{~mol}^{-1[36-39]}$ : the dotted straight line drawn in Fig. 11 corresponds to a $Q$ value of $105 \mathrm{~kJ} \mathrm{~mol}^{-1}$. If a barrier layer is present at the interface, if aluminium is not saturated in iron or if iron contains alloying elements, much higher values of the

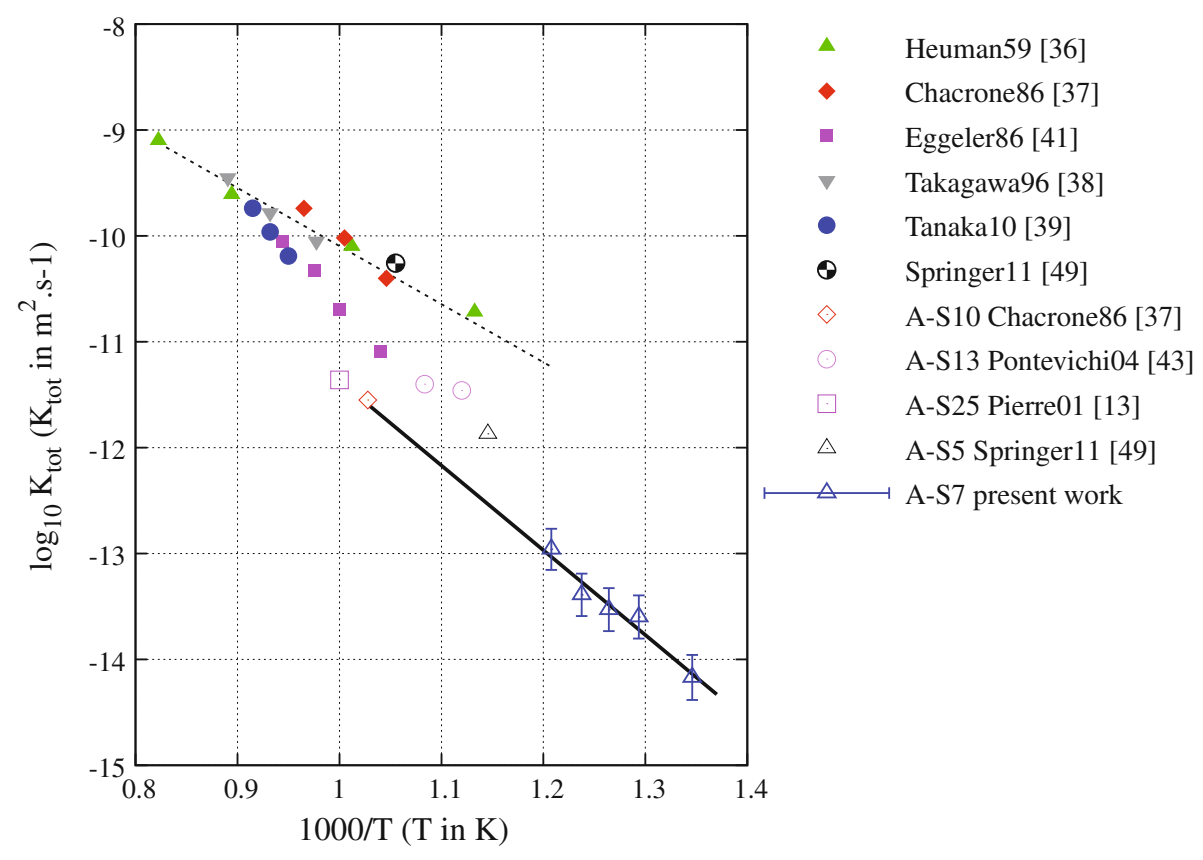

Fig. 11 Arrhenius plot of the growth constant, $K$, for the total reaction layer. Empty triangles with error bar: present work. Empty symbols: previous results obtained in iron saturated Al-Si liquid or semi-liquid alloys. Other plain symbols: results reported for iron or steel reacting with pure aluminium saturated in iron 
activation energy $Q$ can be found (up to $300 \mathrm{~kJ} \mathrm{~mol}^{-1}$ )..$^{[40-42]}$ Addition of silicon to aluminium is known to decrease the value of the growth constant $K$ (see empty symbols in Fig. 11) and to raise the activation energy $Q .^{[9-11,13,37,43-45]}$ Results obtained in the present work after solid state interaction with an iron-saturated $\mathrm{Al}-\mathrm{Si}$ alloy (empty triangles with error bar) are in line with this general trend.

3.2.6 Diffusion Path and Reaction Mechanism. As a general rule for chemical interactions taking place in semiinfinite diffusion couples, the thermally activated parabolic growth of an interface reaction layer characterizes a growth mechanism kinetically controlled by the solid state volume diffusion of atoms through this layer. In view of Fig. 10 and 11 , it is logical to consider that the solid state chemical interaction at the steel/A-S7G03 interface proceeds by such a mechanism. Moreover, the fact that the reaction products tend to arrange themselves into distinct sub-layers according to a unique reaction layer sequence suggests that steady state growth conditions tend to be established. In such steady state conditions, local phase equilibria exist at the different boundaries of the reaction zone and the reaction layer sequence corresponds to a diffusion path in the phase diagram of the relevant system at the temperature of the experiment. ${ }^{[46]}$ For the steel/A-S7G03 semi-infinite couple under study, the reaction layer sequence observed after longterm solution treatment at $535-555{ }^{\circ} \mathrm{C}(808-828 \mathrm{~K})$ is:

$\alpha \mathrm{Fe} / \eta \mathrm{Al}_{5} \mathrm{Fe}_{2}+\tau_{1-9} / \tau_{1} / \tau_{10} / \tau_{2} / \tau_{6} / \mathrm{Al} / \mathrm{Al}-\mathrm{Si}$

It can be seen in Fig. 1 that this sequence effectively corresponds to a diffusion path in the Al-Fe-Si ternary phase diagram (alloying elements other than Si can be neglected since none of them is present in a detectable amount in the reaction products). However, in order to coincide perfectly with the continuous diffusion path drawn in Fig. 1, a solid solution of $\mathrm{Al}$ (and $\mathrm{Si}$ ) in $\alpha \mathrm{Fe}$ and the $\zeta_{\mathrm{Al}_{2}} \mathrm{Fe}$ phase should be featuring in the experimental layer sequence. In fact, these phases may be present but in the form of extremely thin sub-layers. The reason should be the very large difference in the interdiffusion coefficients of $\mathrm{Al}$ and $\mathrm{Fe}$ on one hand in $\alpha \mathrm{Fe}$ and $\zeta \mathrm{Al}_{2} \mathrm{Fe}\left(D \sim 10^{-19} \mathrm{~m}^{2} \mathrm{~s}^{-1}\right.$ at $\left.535^{\circ} \mathrm{C}(808 \mathrm{~K})^{[47,48]}\right)$ and, on the other hand, in the compound $\eta \mathrm{Al}_{5} \mathrm{Fe}_{2}\left(10^{-15}<D<10^{-13} \mathrm{~m}^{2} \mathrm{~s}^{-1}\right.$ at the same temperature ${ }^{[39]}$ ). To support this explanation, it is worth mentioning that $\alpha \mathrm{Fe}$ and $\zeta_{\mathrm{Al}_{2}} \mathrm{Fe}$ were effectively characterized between iron and $\eta \mathrm{Al}_{5} \mathrm{Fe}_{2}$ at a steel/Al interface but transmission electron diffraction after focused ion beam machining was needed. ${ }^{[49]}$

In addition to the existence of local equilibria at the different interfaces, growth of a reaction zone by solid state volume diffusion must obey two other requirements: the mass balance must be preserved and intrinsic diffusion of species can only proceed down their activity gradient. ${ }^{[46]}$ Concerning the mass balance, it can be seen in Fig. 1 that this is preserved since the diffusion path crosses the Fe/A-S7 line joining the end members of the couple. As for the activity gradient, it is worth remarking that for each of the three elements, the variation of its content at the crossing of the reaction zone is not monotonous (Fig. 8). To cross the entire reaction zone, each element has thus to diffuse up its

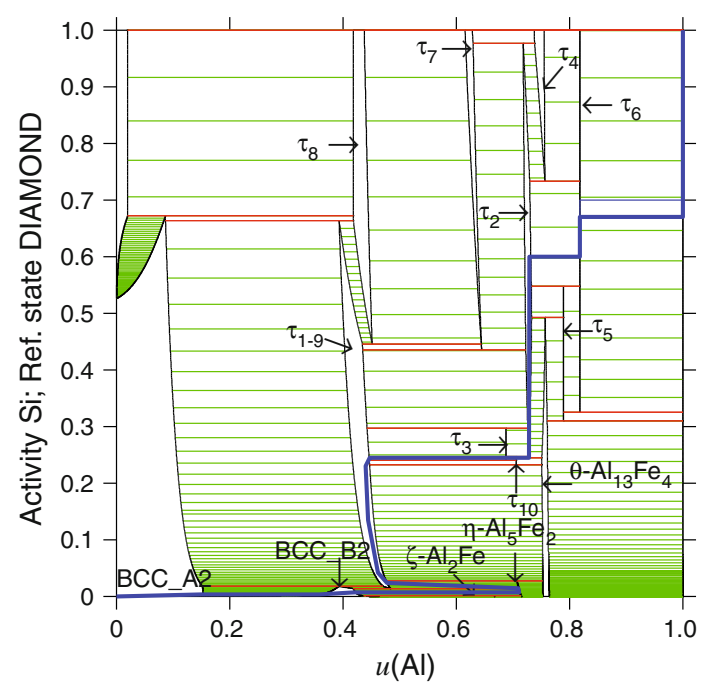

Fig. 12 Diffusion path in the Al-Fe-Si equilibrium phase diagram at $555^{\circ} \mathrm{C}$ represented in silicon activity (the THERMOCALC software and the database from Ref 31 were used to draw the activity phase diagrams)

concentration gradient. By constructing activity diagrams for $\mathrm{Al}, \mathrm{Fe}$ and $\mathrm{Si}$ similar to that presented in Fig. 12, it has been verified that this was not incompatible with intrinsic diffusion down the activity gradient. Again, it is illustrated that in a ternary system, the activity and the concentration of the constituting elements may vary in opposite senses.

In all the reaction zones characterized after heat treatment, the $\eta \mathrm{Al}_{5} \mathrm{Fe}_{2}+\tau_{1-9}$ sub-layer was by far the thickest (it represented from two-thirds to four-fifths of the total reaction zone). This means that it has the fastest rate of growth by solid state volume diffusion compared to the other compounds. Anomalous fast rate interdiffusion in $\eta \mathrm{Al}_{5} \mathrm{Fe}_{2}$ during its formation at a $\mathrm{Fe} / \mathrm{Al}$ interface has been recognized for a long time. ${ }^{[36,39]}$ Considering the crystal structure of the phase (orthorhombic, Cmcm, $a=0.76559 \mathrm{~nm}, b=0.64154 \mathrm{~nm}, c=0.42184 \mathrm{~nm})$ with Al sites not fully occupied along directions parallel to the [001] row, ${ }^{[50]}$ Heumann and Dittrich proposed that growth preferentially proceeds in that direction by fast rate diffusion of $\mathrm{Al}$ atoms only. ${ }^{[36]}$ According to Eggeler et al., ${ }^{[10]}$ silicon would slow down the $\mathrm{Al}$ diffusion process by occupying the Al vacancies. In experiments with and without graphite markers in which a $\eta \mathrm{Al}_{5} \mathrm{Fe}_{2}+\tau_{1-9}$ sub-layer was formed, ${ }^{[13]}$ fast rate growth of $\eta \mathrm{Al}_{5} \mathrm{Fe}_{2}$ in the [001] direction and by unidirectional diffusion of $\mathrm{Al}$ atoms were confirmed.

This anomalous fast rate growth of $\eta \mathrm{Al}_{5} \mathrm{Fe}_{2}$ by unidirectional diffusion of $\mathrm{Al}$ atoms is of great importance since it is at the origin of an irreversible damaging effect on the metallurgical bond. Indeed the unbalanced diffusion of $\mathrm{Al}$ atoms to the $\mathrm{Fe} / \eta \mathrm{Al}_{5} \mathrm{Fe}_{2}$ reaction front where $\eta \mathrm{Al}_{5} \mathrm{Fe}_{2}$ is growing results in the formation of voids in the reaction zone and, more especially, at its outer part nearby the $\tau_{6} / \mathrm{Al}$ interface (Fig. 13). Development of such a porosity has been frequently observed in multiphase solid state diffusion couples ${ }^{[51,52]}$ and in most cases attributed to the Kirkendall 
effect. ${ }^{[53,54]}$ As a result of the development of Kirkendall voids, both the contact surface area and the bond strength decrease. ${ }^{[55]}$

3.2.7 Effect of Silicon Content in the Alloy. To examine the influence of silicon content in the Al-Si alloy, XES plates were aluminized by dip-coating as before but instead of an A-S7G03 alloy, synthetic A-S3 (3 wt.\% Si) and A-S17 (17 wt.\% Si) alloys were used. After solution treatment for $20 \mathrm{~h}$ at $535{ }^{\circ} \mathrm{C}(808 \mathrm{~K})$, the morphology and constitution of the interface transition zones in XES/A-S3 and XES/A-S17 samples were very much the same as previously. Like the $\mathrm{XES} / \mathrm{A}-\mathrm{S} 7 \mathrm{G} 03$ couple after $20 \mathrm{~h}$ of isothermal holding, they consisted of an inner sub-layer of $\eta+\tau_{1-9}$ and of an outer sub-layer of $\tau_{6}$ separated by a multi-phase brown-grey transition zone. Silicon crystals and $\tau_{6}$ platelets were also present in the surrounding Al-Si alloy. The only difference was in the total thickness of the reaction zone which was slightly smaller for the A-S17 alloy, 25-35 $\mu \mathrm{m}$, than for the A-S3 and A-S7G03 alloys, about $50 \mu \mathrm{m}$. This change was mainly due to a variation in thickness of the $\eta+\tau_{1-9}$ inner sub-layer. As already mentioned in section 3.2.3, silicon strongly influences the rate of growth of the $\eta \mathrm{Al}_{5} \mathrm{Fe}_{2}$ compound: the higher its silicon activity, the slower the rate of growth. Although the three Al-Si alloys are two-phase in the solid state, which implies chemical activities for Al and Si that are constant and close to the unity, the flux of silicon atoms and the local activity of this element in the inner $\eta+\tau_{1-9}$ sub-layer may be slightly higher, as growth proceeds, for an A-S17 alloy coating than for an A-S7 or an A-S3. This would explain the variation in thickness.

It is interesting to note that the reaction zone in four sublayers shown in Fig. 7 is almost the same as that observed by Springer et al. ${ }^{[49}$ for a steel/A-S5 couple reacted for $16 \mathrm{~h}$ at $600{ }^{\circ} \mathrm{C}(873 \mathrm{~K})$ in the semi-solid state. This reaction zone

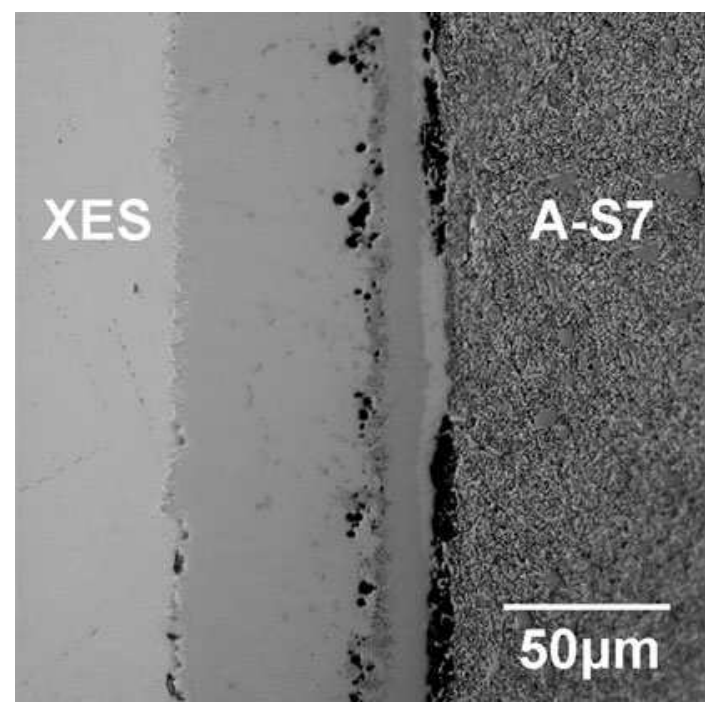

Fig. 13 Kirkendall voids in the XES/A-S7G03 reaction layer after long-term heat treatment at $535{ }^{\circ} \mathrm{C}(808 \mathrm{~K})$. Voids have preferentially developed at the outer part of the $\tau_{6}$ sub-layer (near the $\tau_{6} /$ alloy interface) but some have also coalesced in the $\tau_{1-9}$ sub-layer is also very similar to that previously characterized at the surface of an iron plate after $16 \mathrm{~h}$ of isothermal holding at $727{ }^{\circ} \mathrm{C}$ in a liquid Al-Si alloy saturated in iron and silicon (Fe/A-S25 couple). ${ }^{[13]}$ In the latter case, the only difference lies in the constitution of the outer layer made of $\tau_{6}$ at $535{ }^{\circ} \mathrm{C}$ and of $\tau_{4}$ at $727{ }^{\circ} \mathrm{C}$, but this difference is logical since $\tau_{6}$ is not stable above $667{ }^{\circ} \mathrm{C}(940 \mathrm{~K}) .{ }^{[34]}$ The fact that the $K$ value determined at $727{ }^{\circ} \mathrm{C}$ for the Fe/A-S25 couple with a liquid saturated in $\mathrm{Si}$, and thus with a $\mathrm{Si}$ activity close to 1 , is located on the linear fit of the present results (see the solid line drawn in Fig. 11) suggests both that the same growth mechanism would be operating whatever the state of the alloy (liquid or solid) and that the growth rate is correlated with the $\mathrm{Si}$ activity. The other $K$ values reported in Fig. 11 for other Fe/Al-Si couples (empty symbols) more or less deviate from the solid line. These deviations are due in part to different silicon activities in the Al-Si alloy: indeed, activities vary from 0.8 for $\mathrm{A}-\mathrm{S} 13$ at $620{ }^{\circ} \mathrm{C}$ to 0.59 for A-S5 at $600{ }^{\circ} \mathrm{C}$ (semi-solid state). Other parameters, such as the presence of alloying elements in steel or the fact that the alloy is not fully saturated in iron, also have to be taken into account, as already mentioned in section 3.2.3.

\subsection{Moulded Blocks Versus Aluminized Plates}

In Fig. 14 the total reaction layer thicknesses measured after heat treatment at $535^{\circ} \mathrm{C}(808 \mathrm{~K})$ are compared with, on one hand, XES/A-S7G03 aluminized steel plates and, on the other hand, $5 \mathrm{~mm}$ thick slices cut in moulded blocks with a steel insert. It can be seen that, although initially larger, the mean thickness of the interface reaction zone increases at a slower rate for slices than for aluminized plates. Moreover, for slices a negative deviation to the parabolic growth law is obvious. After 15-20 h heat treatment, a porous zone analogous to that shown in Fig. 13 was systematically observed at the $\tau_{6} / \mathrm{Al}$ slice interface whereas such a zone was not yet detectable in plates heat-treated under identical conditions. For longer

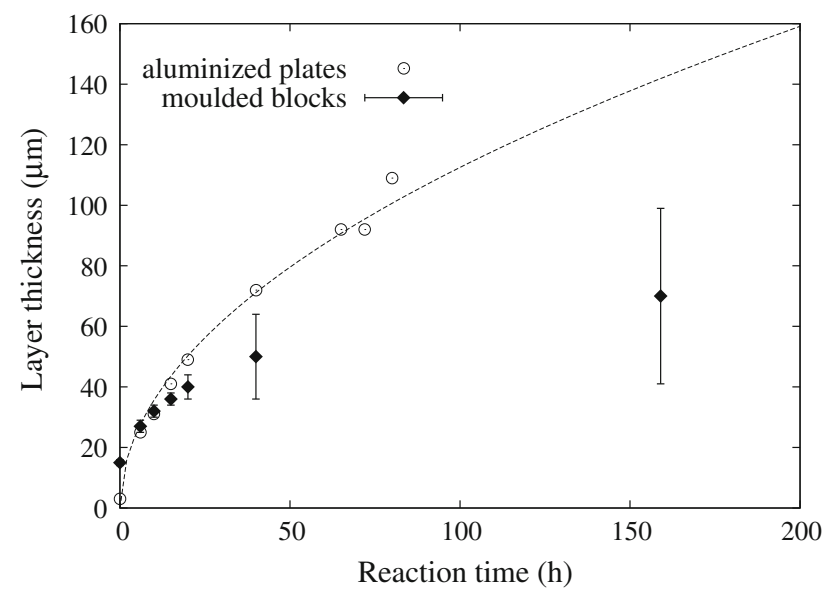

Fig. 14 Variation with heat treatment time of the total reaction layer thickness at the XES/A-S7G03 interface in aluminized plates (empty circles) and slices cut in moulded blocks. The dotted line represents the ideal parabolic growth law 
isothermal holding times, connected holes resulting from the Kirkendall effect previously mentioned were systematically observed in the slices and it became difficult to appreciate a mean thickness: in some rare places, growth had continued and four sub-layers were still observable whereas in other places, growth had stopped. This is reflected in Fig. 14 by considerable error bar widening.

To obey the parabolic growth law, the contact surface area at the $\tau_{6}$ /alloy interface where Kirkendall voids develop must remain as large as possible. If no external pressure is applied, meeting this requirement implies plastic deformation of the alloy. In this regard, the geometry of the aluminized steel plates, which are covered with a thin and easily deformable alloy film, is much more favorable than that of slices in which the steel plate is surrounded by a massive alloy disk difficult to deform. Moreover, the thin alloy layer covering the aluminized plates is continuous and can protect the underlying reaction zone from oxidation whereas for slices cut in blocks, paths for oxygen penetration into the reaction zone exist on both faces. In short, the Kirkendall effect is more pronounced and the penetration of oxygen in the reaction layer easier for slices than for aluminized plates. The latter effect of oxygen penetration was evidenced by an experiment in which the entire block was heat-treated at $535{ }^{\circ} \mathrm{C}(808 \mathrm{~K})$ for $160 \mathrm{~h}$; slices were cut only afterwards. In comparison with a slice cut before heat-treatment, the reaction zone was effectively less irregular and significantly thicker: $80-100 \mu \mathrm{m}$ instead of 40-100 $\mu \mathrm{m}$.

Finally, it will be recalled that experiments on slices were carried out to obtain a better simulation of T6 solution treatment applied to a steel/Al-Si insert moulded casting. It thus clearly appears that if a metallurgical bond initially exists at the insert/alloy interface, the combined effects of Kirkendall voids formation and oxidation upon solution treatment will result in severe damage to the joint. More precisely, when such joints were characterized by 4-points bending, an acceptable bond strength was obtained before heat treatment, ${ }^{[56]}$ whereas a solution treatment of only $2 \mathrm{~h}$ at $535{ }^{\circ} \mathrm{C}$ led to systematic failure of the steel/A-S7G03 joint during cooling.

\section{Conclusion}

The aim of the present work was to get a better insight into the solid state interface reaction processes that may develop between an iron base insert and a classical $\mathrm{Al}-\mathrm{Si}$ foundry alloy (A-S7G03 or A356) in bimetallic parts made of these constituents and subjected to solution heat treatment at $520-540{ }^{\circ} \mathrm{C}(793-813 \mathrm{~K})$.

It has been shown that isothermal holding of a low carbon steel plate at $535{ }^{\circ} \mathrm{C}(808 \mathrm{~K})$ in an iron-saturated AS7G03 alloy results in the growth of a multi-phase interface reaction layer by solid state chemical interaction. As long as intimate contact is maintained at the steel/alloy interface, the reaction layer develops according to a nearly parabolic growth law $x^{2}=K \cdot t-b$, where $x$ is the total layer thickness (in $\mathrm{m}$ ), $t$ the reaction time (in s) and $K$ the parabolic growth constant (in $\mathrm{m}^{2} \mathrm{~s}^{-1}$ ). In the temperature range $470-560{ }^{\circ} \mathrm{C}$ $(743-833 \mathrm{~K})$, the growth constant, $K$, is thermally activated. $T$ being the temperature in Kelvin and $R$ the gas constant $\left(R=8.314 \mathrm{~J} \mathrm{~K}^{-1} \mathrm{~mol}^{-1}\right)$, the growth constant $K$ expresses as $K=K_{0} \exp (-Q / R T)$ with $K_{0}=4.37 \times 10^{-4} \mathrm{~m}^{2} \mathrm{~s}^{-1}$ and $Q=153 \mathrm{~kJ} \mathrm{~mol}^{-1}$.

Five binary and ternary compounds of the Al-Fe-Si system were characterized in the growing reaction zone: $\eta \mathrm{Al}_{5} \mathrm{Fe}_{2}, \tau_{1-9}, \tau_{2}, \tau_{6}$ and $\tau_{10}$. As the heat treatment time increased, these compounds tended to gather into different sub-layers. For long heat treatment times, more than $40 \mathrm{~h}$ of isothermal holding, they arranged themselves into the following reaction layer sequence: $\alpha \mathrm{Fe} / \eta \mathrm{Al}_{5} \mathrm{Fe}_{2}+\tau_{1-9} / \tau_{1} /$ $\tau_{10} / \tau_{2} / \tau_{6} / \mathrm{Al} / \mathrm{Al}-\mathrm{Si}$. This sequence corresponds to a diffusion path in the Al-Fe-Si phase diagram. All these features are consistent with a chemical reaction process controlled by solid state volume diffusion of the elements $\mathrm{Al}, \mathrm{Si}$ and $\mathrm{Fe}$ through the entire reaction layer down their activity gradient.

Under conventional T6 solution treatment conditions, i.e. when massive bimetallic parts are heated at $520-540{ }^{\circ} \mathrm{C}$ under air without external applied pressure, a negative deviation to the parabolic growth law is however very likely. The main reason for this deviation is the growth of Kirkendall voids at the alloy/reaction layer interface as a consequence of the unbalanced diffusion of aluminium atoms through the reaction zone to feed the growth of the aluminium-rich phase $\eta \mathrm{Al}_{5} \mathrm{Fe}_{2}$. As these voids coalesce at the $\tau_{6} / \mathrm{Al}$ interface and within the non-ductile outer $\tau_{6}$ sub-layer, the contact surface area between the end members of the diffusion couple is gradually reduced. This not only slows down the solid state diffusion process but also weakens the metallurgical bond. If at the same time, oxygen can penetrate in the bond through pre-existing cracks, the wedge effect of the aluminium oxide growing in the crack and in the voids will accentuate damage to the interface bond.

\section{Acknowledgments}

Chemical microanalyses have been performed by "Service Central d'Analyse, SCA, CNRS". SCA CNRS, Solaize. SEM and EPMA characterizations were performed at the "Centre Technologique des Microstructures, CT $\mu$, Université Lyon 1". Many thanks to the members of this service for their assistance. The assistance of D. Grevey and A. Matthieu Univ Bourgogne Le Creusot is also gratefully acknowledged.

\section{References}

1. N. Miyamoto, et al., Insert Casting Component, Cylinder Block, Method for Forming Coating on Insert Casting Component and Method for Manufacturing Cylinder Block, U.S. Patent WO2007007826, 18 Jan 2007

2. M.J. Nunney, Light and Heavy Vehicle Technology, Fourth Edition, 4th ed., Butterworth-Heinemann, 2006

3. S. Bennett, Modern Diesel Technology: Diesel Engines, 4th ed., Thomson Delmar Learning, Division of Thomson Learning, 2009 
4. K. Zimnik, M. Schöbel, B. Reitinger, H.P. Degischer, and U. Noster, Interface of Steel Inserts in Al-Si Alloy Castings, Verbundwerkstoffe, Wiley-VCH Verlag GmbH \& Co. KGaA, 2009, p 527-534

5. G. Sierra, P. Peyre, F. Deschaux Beaume, D. Stuart, and G. Fras, Galvanised Steel to Aluminium Joining by Laser and GTAW Processes, Mater. Charact., 2008, 59(12), p 1705-1715

6. J. Pan, M. Yoshida, G. Sasaki, H. Fukunaga, H. Fujimura, and M. Matsuura, Ultrasonic Insert Casting of Aluminum Alloy, Scripta Mater, 2000, 43(2), p 155-159

7. K.H. Choe, K.S. Park, B.H. Kang, K.Y. Kim, K.W. Lee, and M.H. Kim, Study of the Interface Between Steel Insert and Aluminum Casting in EPC, J. Mater. Sci. Technol. (Shenyang, China), 2008, 24(1), p 60-64

8. G. Guertler, Compound Casting, Aluminium (Isernhagen, Germany), 1969, 45(6), p 368-373

9. Y. Uchida, M. Fujita, and Y. Hirose, Effects of Silicon in Coating Bath on the Reaction Between Molten Aluminum and Steel Sheet, Kinzoku Hyomen Gijutsu, 1982, 33(10), p 537543

10. G. Eggeler, W. Auer, and H. Kaesche, On the Influence of Silicon on the Growth of the Alloy Layer During Hot Dip Aluminizing, J. Mater. Sci., 1986, 21(9), p 3348-3350

11. P. Vaillant and J.P. Petitet, Interactions Under Hydrostatic Pressure of a Mild Steel with Liquid Aluminium Alloys, J. Mater. Sci., 1995, 30(18), p 4659-4668

12. P. Dillmann, B. Regad, and G. Moulin, Intermetallic Phase Identification on Al-Si-Fe Hot Dip Coated Steel by X-Ray Synchrotron Microbeam, J. Mater. Sci. Lett., 2000, 19(10), p 907-910

13. D. Pierre, F. Barbeau, M. Peronnet, F. Bosselet, and J.-C. Viala, Reaction Layer Sequences at the Interface Between Iron and Al-Si Alloys, DIMAT 2000, Y. Limoge and J.L. Bocquet, Ed., July 17-21, 2000 (Paris), Scitec, 2000, p 1593-1598

14. S.P. Gupta, Intermetallic Compound Formation in Fe-AlSi Ternary System: Part I, Mater. Charact., 2002, 49(4), p 269-291

15. T. Maitra and S.P. Gupta, Intermetallic Compound Formation in Fe-Al-Si Ternary System: Part II, Mater. Charact., 2002, 49(4), p 293-311

16. W. Fragner, B. Zberg, R. Sonnleitner, P.J. Uggowitzer, and J.F. Löffler, Interface Reactions of Al and Binary Al-Alloys on Mild Steel Substrates in Controlled Atmosphere, Mater. Sci. Forum, 2006, 519-521, p 1157-1162

17. T.-S. Shih and S.-H. Tu, Interaction of Steel with Pure Al, Al-7Si and A356 Alloys, Mater. Sci. Eng. A, 2007, 454-455, p 349-356

18. I.G. Brodova, O.A. Chikova, M.A. Vityunin, I.G. Shirinkina, T.I. Yablonskikh, and L.V. Elokhina, Structure of Diffusion Layers That are Formed Upon Spreading of Al-Si Melts Over the Surface of St3 Steel, Phys. Met. Metallogr., 2010, 109(6), p 626-631

19. A. Bouayad, C. Gerometta, M. Radouani, and A. Saka, Interface Characterization in Aluminum Alloy Casting Reinforced with SG Iron Inserts, J. Adv. Res. Mech. Eng., 2010, 1, p 226-231

20. G. Durrant, M. Gallerneault, and B. Cantor, Squeeze Cast Aluminium Reinforced with Mild Steel Inserts, J. Mater. Sci., 1996, 31(3), p 589-602

21. J.C. Viala, M. Peronnet, F. Barbeau, F. Bosselet, and J. Bouix, Interface Chemistry in Aluminium Alloy Castings Reinforced with Iron Base Inserts, Compos. Part A: Appl. Sci. Manuf., 2002, 33(10), p 1417-1420

22. O. Dezellus, B. Digonnet, M. Sacerdote-Peronnet, F. Bosselet, D. Rouby, and J.C. Viala, Mechanical Testing of Steel/
Aluminium-Silicon Interfaces by Pushout, Int. J. Adhes. Adhes., 2007, 27, p 417-421

23. J.G. Kaufman and E.L. Rooy, Aluminum Alloy Castings: Properties, Processes and Applications, Illustrated edition, ASM International, 2004

24. A. Thirugnanam, K. Sukumaran, U.T.S. Pillai, K. Raghukandan, and B.C. Pai, Effect of $\mathrm{Mg}$ on the Fracture Characteristics of Cast Al-7Si-Mg Alloys, Mater. Sci. Eng. A, 2007, 445-446, p 405-414

25. G. Ghosh, Aluminium-Iron-Silicon, Ternary Alloys, Vol 5, G. Petzow and G. Effenberg, Ed., VCH, Weinheim, 1992, p 394-438

26. G. Ghosh, Al-Fe-Si (Aluminium-Iron-Silicon), Light Metal Systems, Part 2, Vol 11A2, G. Effenberg and S. Ilyenko, Ed., Springer-Verlag, Berlin, 2005

27. Z.-K. Liu and Y.A. Chang, Thermodynamic Assessment of the Al-Fe-Si System, Metall. Mater. Trans. A, 1999, 30(4), p 1081-1095

28. F. Bosselet, S. Pontevichi, M. Sacerdote-Peronnet, and J.C. Viala, Affinement expérimental de l'isotherme Al-Fe-Si a $1000 \mathrm{~K}$, Journal de Physique IV (Proceedings), 2004, 122, p 6, in French

29. N. Krendelsberger, F. Weitzer, and J.C. Schuster, On the Reaction Scheme and Liquidus Surface in the Ternary System Al-Fe-Si, Metall. Mater. Trans. A, 2007, 38(8), p 1681-1691

30. V. Raghavan, Al-Fe-Si (Aluminum-Iron-Silicon), J. Phase Equilib. Diffus., 2009, 30(2), p 184-188

31. Y. Du et al., A Thermodynamic Description of the Al-Fe-Si System Over the Whole Composition and Temperature Ranges via a Hybrid Approach of CALPHAD and Key Experiments, Intermetallics, 2008, 16(4), p 554-570

32. L. Eleno, J. Vezelý, B. Sundman, M. Cieslar, and J. Lacaze, Assessment of the Al Corner of the Ternary Al-Fe-Si System, Mater. Sci. Forum, 2010, 649, p 523-528

33. V. Raghavan, Al-Fe-Si (Aluminum-Iron-Silicon), J. Phase Equilib. Diffus., 2010, 32(2), p 140-142

34. S. Pontevichi, F. Bosselet, M. Peronnet, and J. C. Viala, Stabilité thermique de la phase $\beta \mathrm{A} 15 \mathrm{FeSi}$ dans le systèmeternaire Al-Fe-Si, Journal de Physique IV (Proceedings), 2004, 113, p 4, in French

35. V.I. Dybkov, Reaction Diffusion and Solid State Chemical Kinetics, 2nd ed., Trans Tech Pubn, 2010

36. T. Heumann and S. Dittrich, Uber die Kinetik der Reaktion von festem und flûssigem Aluminium mit Eisen, Zeitschrift fur Metallkunde, 1959, 50, p 617-625, in German

37. A. Chacrone, "Etude de la formation de la couche d'alliage lors des revêtements d'acier par Al et Al-Si," Ph.D. thesis, Metz (France), 1986, in French

38. T. Takagawa, T. Momono, and H.G. Katayama, Formation of Alloyed Layer on Steel Surface by Immersion into Molten Aluminum Alloys, Chuzo Kogaku, 1996, 68, p 975-980

39. Y. Tanaka and M. Kajihara, Kinetics of Isothermal Reactive Diffusion Between Solid $\mathrm{Fe}$ and Liquid Al, J. Mater. Sci., 2010, 45(20), p 5676-5684

40. S.G. Denner and R.D. Jones, Kinetic Interactions Between Al and Iron/Steel, Met. Technol., 1977, 4, p 167-174

41. G. Eggeler, W. Auer, and H. Kaesche, Reaction Between Low Alloyed Steel and Aluminium Melts Between 670 and $800{ }^{\circ} \mathrm{C}$, Zeitschrift fur Metallkunde, 1986, 77, p 239-244

42. D. Naoi and M. Kajihara, Growth Behavior of $\mathrm{Fe}_{2} \mathrm{Al}_{5}$ During Reactive Diffusion Between $\mathrm{Fe}$ and $\mathrm{Al}$ at SolidState Temperatures, Mater. Sci. Eng. A, 2007, 459(1-2), p 375382

43. S. Pontevichi, "Réactions chimiques d'interface entre fer solide et alliages Al-Si liquides. Applications à l'insertion à la 
coulée et au soudo-brasage laser," Ph.D. thesis, Lyon (France), 2004, in French

44. E. Gebhardt and W. Obrowski, Reaktionen von festem eisen mit schmelzen aus aluminium und aluminiumlegierungen, Zeitschrift fur Metallkunde, 1953, 44(4), p 154-160

45. P.R. Calvillo, L. Suarez, and Y. Houbaert, Al-Si-Fe Intermetallics on Fe-Substrates during Hot-Dipping, Defect Diffus. Forum, 2010, 297-301, p 1042-1047

46. F.J.J. van Loo, Multiphase Diffusion in Binary and Ternary Solid-State Systems, Prog. Solid State Chem., 1990, 20(1), p 47-99

47. H. Mehrer, Diffusion in Solids, Vol 155, Springer, Berlin, 2007

48. Y.-W. Cui et al., Revisiting Diffusion in Fe-Al Intermetallics: Experimental Determination and Phenomenological Treatment, Scripta Mater., 2010, 62(4), p 171-174

49. H. Springer, A. Kostka, E.J. Payton, D. Raabe, A. KaysserPyzalla, and G. Eggeler, On the Formation and Growth of Intermetallic Phases During Interdiffusion Between LowCarbon Steel and Aluminum Alloys, Acta Mater., 2011, 59(4), p 1586-1600
50. U. Burkhardt, Y. Grin, M. Ellner, and K. Peters, Structure Refinement of the Iron-Aluminium Phase with the Approximate Composition $\mathrm{Fe}_{2} \mathrm{Al}_{5}$, Acta Crystallogr. Sect. B Struct. Sci., 1994, 50(3), p 313-316

51. A. Borgenstam and M. Hillert, Massive Transformation in the Fe-Ni System, Acta Mater., 2000, 48(11), p 2765-2775

52. D. Tomus et al., Fabrication of Shape Memory TiNi Foils via Ti/ Ni Ultrafine Laminates, Scripta Mater., 2003, 48(5), p 489-494

53. A. Smigelskas and E. Kirkendall, Zinc Diffusion in AlphaBrass, Trans. AIME, 1947, 171, p 130-142

54. A. Paul, M.J.H. van Dal, A.A. Kodentsov, and F.J.J. van Loo, The Kirkendall Effect in Multiphase Diffusion, Acta Mater, 2004, 52(3), p 623-630

55. L.G. Feinstein and J.B. Bindell, The Failure of Aged $\mathrm{Cu}-\mathrm{Au}$ Thin Films by Kirkendall Porosity, Thin Solid Films, 1979, 62(1), p 37-47

56. M. Zhe, O. Dezellus, G. Parry, M. Braccini, and J.C. Viala, Modified 4-Point Bending Test for Adhesion Measurement at the Interface of Iron Coated with Aluminum Casting Alloy, J. Adhes. Sci. Technol., 2001, doi:10.1163/016942411X559049 